\title{
SEGREGATION OF ELEMENTS IN HIGH REFRACTORY CONTENT SINGLE CRYSTAL NICKEL BASED SUPERALLOYS
}

\author{
E. C. Caldwell, F. J. Fela, G. E. Fuchs \\ University of Florida, Dept. of Materials Science \& Engineering \\ 116 Rhines Hall, Gainesville, FL 32611, USA \\ Keywords: Superalloys, Partitioning; Single Crystals, Solidification
}

\begin{abstract}
Nickel based superalloys are widely used in industry where high temperature strength and corrosion resistance are required, but these alloys are very complex in nature. They are typically made up of 10 to 15 different elemental additions to the nickel base. Additions of $\mathrm{Cr}, \mathrm{Co}, \mathrm{W}, \mathrm{Ta}, \mathrm{Al}, \mathrm{Ti}, \mathrm{Re}, \mathrm{Mo}$, and in some alloys $\mathrm{Ru}$ are all common. Each of these additions can affect the as-cast microstructure due to differences in elemental segregation. A better understanding of the effects of the additions on the segregation of all of the elements in the alloy can help make improvements in processing of current alloys and development of new alloys. Therefore, the effect of several common alloying additions on the resulting solidification segregation and phase transformation temperatures were evaluated. In general, an increase in the degree of elemental segregation was observed with increasing additions of each of the elements listed above, except $\mathrm{Co}$ and Mo. Increased levels of Co and Mo resulted in reductions in the segregation of most of the elements in the alloy.
\end{abstract}

\section{Introduction}

Nickel-based superalloys can trace their origins back to the need for structural materials with high temperature stability and strength and ultimately to the development of gas turbine engines. The compositions of nickel based superalloys have evolved from very simple to very complex, due to constant need for higher temperature capabilities, which were required to meet the design goals for new, higher performance engines [1-5].

The $\gamma$ matrix of a Ni-based superalloy is a disordered FCC lattice, made up primarily of $\mathrm{Ni}, \mathrm{Cr}, \mathrm{Co}, \mathrm{Mo}, \mathrm{W}$ and, in some cases, $\mathrm{Re}$ and $\mathrm{Ru}$. The addition of $\mathrm{Re}$ is often used as reference point between first generation superalloys ( 0 at $\%$ Re), and second generation superalloys ( 1 at $\% \mathrm{Re})$. Eventually, third generation superalloys were developed that contained 2 at $\%$ Re along with other additions $[3,4]$. Today, fourth generation superalloys are being developed with additions of $\mathrm{Ru}$ [5]. An ordered $\gamma$ '$\mathrm{Ni}_{3}(\mathrm{Al}, \mathrm{Ti}, \mathrm{Nb}, \mathrm{Ta})$ phase precipitates from the matrix at relatively high temperatures and strengthens the alloy. During casting, dendrites that are predominately $\gamma$ form with a $\gamma-\gamma^{\prime}$ eutectic interdendritic region surrounding the dendrites. The $\gamma$ ' phase is also present in the dendrite core, but are finer in size since the precipitate from the $\gamma$ matrix during cooling. The elements added to the alloy typically show a preference to which phase they partition during solidification. $\mathrm{Co}, \mathrm{W}$ and Re have been shown to partition to the dendrite core, while $\mathrm{Ni}, \mathrm{Ta}, \mathrm{Ti}$, and $\mathrm{Al}$ tend to segregate to the interdendritic region $[4,6]$. A segregation coefficient, $\mathrm{k}$ ', which is usually defined as the ratio of the concentration (in $w t \%$ ) of the element in the dendrite core to the concentration of the element in the interdendritic region, or

$k^{\prime}=\frac{x_{i, \text { Dendrite }}}{x_{i, \text { Interdendritic }}}$, where $\mathrm{x}_{\mathrm{i}}$ is the concentration of each specific element in wt\% [7]. k' values of less than 1 indicate segregation to the interdendritic region. While k' values of greater than 1 indicate segregation to the dendrite core.

The directional solidification (DS) approach was developed to produce single crystal casting (SX). In both DS and SX, $\gamma$ dendrites are the first solid to form, typically at temperatures just below the liquidus temperature, and the solid that forms in the interdendritic region is the last to solidify at a temperature below the solidus due to elemental segregation during solidification $[8,9]$. The only way to eliminate this elemental segregation is to heat treat the material at temperatures above the $\gamma$-solvus and below the solidus temperatures. This temperature range is referred to as the heat treatment window. Clearly, the chemical composition of the alloy would be expected to affect the degree and amount of segregation, and will also influence the solidus temperature, and the $\gamma$ '-solvus temperature of the alloy.

The composition of single crystal alloys are designed to allow complete solutioning of the $\gamma$, to optimize the mechanical properties. These solution heat treatments also can reduce or eliminate the elemental segregation in as-cast materials. Since the degree of segregation and the size of the heat treatment window are dependent on the overall composition of the alloy, the heat treatment time and temperatures to allow elimination of the segregation are dependent on the alloy chemistry. For some alloy compositions, the heat treatment times can be become very long and the heat treatment temperatures can be in excess of $1300^{\circ} \mathrm{C}$, which can result in increased cost. However, the properties of the alloys are also a function of the degree of homogenization during the solution heat treatment, with improved properties reported in alloys with increased homogeneity $[10,11]$. In order to reduce the processing cost, by reducing the heat treatment requirement, without degrading the properties of the alloys, a reduction in the degree of segregation would be required. Since the degree of segregation is a function of composition, it is necessary to understand the effect of alloy composition on the segregation of the elements in the alloy during solidification. The purpose of this study is to evaluate the effect of composition on the solidification segregation of model third generation Ni-base superalloy single crystals. 
Table 1: Compositions of Experimental Single Crystal Alloys (shaded regions indicate specific change off baseline)

\begin{tabular}{|c|c|c|c|c|c|c|c|c|c|c|c|c|}
\hline Alloy ID & $\mathbf{N i}$ & $\mathrm{Cr}$ & Co & Mo & $\mathbf{W}$ & Ta & $\operatorname{Re}$ & Al & $\mathbf{T i}$ & Hf & $\mathbf{R u}$ & Comments \\
\hline \multirow[t]{2}{*}{ LMSX-1 } & Bal & 4.10 & 12.20 & & 5.85 & 8.60 & 5.90 & 5.55 & & 0.10 & & Baseline \\
\hline & 62.0 & 5.00 & 13.00 & & 2.00 & 3.00 & 2.00 & 13.00 & & 0.05 & & Atomic \% Composition \\
\hline LMSX-2 & Bal & 4.10 & 8.00 & & 5.85 & 8.60 & 5.90 & 5.55 & & 0.10 & & Reduced Co (8 at\%) \\
\hline LMSX-3 & Bal & 4.10 & 4.00 & & 5.85 & 8.60 & 5.90 & 5.55 & & 0.10 & & Minimum Co $(4 \mathrm{at} \%)$ \\
\hline LMSX-4 & Bal & 6.15 & 12.20 & & 5.85 & 8.60 & 5.90 & 5.55 & & 0.10 & & High Cr (7 at $\%)$ \\
\hline LMSX-5 & Bal & 2.10 & 12.20 & & 5.85 & 8.60 & 5.90 & 5.55 & & 0.10 & & Low $\mathrm{Cr}(3 \mathrm{at} \%)$ \\
\hline LMSX-6 & Bal & 4.10 & 12.20 & & 8.60 & 8.60 & 5.90 & 5.55 & & 0.10 & & High W (3 at $\%)$ \\
\hline LMSX-7 & Bal & 4.10 & 12.20 & 1.60 & 3.10 & 8.60 & 5.90 & 5.55 & & 0.10 & & Low W $(1$ at $\%)+1$ at $\%$ Mo \\
\hline LMSX-8 & Bal & 4.10 & 12.20 & 1.60 & 5.85 & 8.60 & 5.90 & 5.55 & & 0.10 & & $+1 \mathrm{at} \% \mathrm{Mo}$ \\
\hline LMSX-9 & Bal & 4.10 & 12.20 & & 5.85 & 8.60 & 0.00 & 5.55 & & 0.10 & & 0 at $\% \operatorname{Re}$ \\
\hline LMSX-10 & Bal & 4.10 & 12.20 & & 5.85 & 8.60 & 2.95 & 5.55 & & 0.10 & & $1 \mathrm{at} \% \mathrm{Re}$ \\
\hline LMSX-11 & Bal & 4.10 & 12.20 & & 5.85 & 8.60 & 8.70 & 5.55 & & 0.10 & & $3 \mathrm{at} \% \mathrm{Re}$ \\
\hline LMSX-16 & Bal & 4.10 & 12.20 & & 5.85 & 8.60 & 5.90 & 5.55 & & 0.10 & 1.60 & $+1 \mathrm{at} \% \mathrm{Ru}$ \\
\hline LMSX-17 & $\mathrm{Bal}$ & 4.10 & 12.20 & & 5.85 & 8.60 & 5.90 & 5.55 & & 0.10 & 3.20 & +2 at $\% \mathrm{Ru}$ \\
\hline CMSX-10 & $\mathrm{Bal}$ & 3.00 & 4.00 & 0.60 & 6.00 & 8.00 & 6.00 & 5.75 & & 0.10 & & \\
\hline Rene N6 & Bal & 4.50 & 12.50 & 1.10 & 5.75 & 7.50 & 6.00 & 5.35 & & 0.15 & & \\
\hline
\end{tabular}

\section{Materials and Experimental Procedure}

$\underline{\text { Material }}$

A model third generation Ni-based alloy was selected as a baseline material, and designated LMSX-1. This alloy is a simplified version of the commercial alloys, René N6 and CMSX-10. Various additions and modifications were made to the base alloy composition resulting in a total of 13 alloys (Table 1) that were used to study the effects of alloying additions on the as-cast microstructures, solidification defects, segregation behavior. All of the alloy modifications selected for evaluation are commonly observed in first, second, and third generation superalloys. In addition, two (2) alloys were modified with $\mathrm{Ru}$ to approximate fourth generation superalloy chemistries to examine the effect of $\mathrm{Ru}$ on as-solidified structures.

A $10-12 \mathrm{Kg}$ master heat was prepared for each alloy at PCC Airfoils (Minerva, $\mathrm{OH}$ ). One mold of single crystal bars was processed for each alloy. Single crystal samples $(1.27 \mathrm{~cm}$ dia $\mathrm{x}$ $20 \mathrm{~cm}$ long) were processed and cast in the $<001>$ orientation using standard selectors and high gradient processing techniques in a Bridgeman-type withdrawal furnace. The thermal gradient during processing was estimated to be about $30-40 \% \mathrm{~cm}$ with a constant withdrawal rate of $20 \mathrm{~cm} / \mathrm{hr}$. Any sample with a misorientation greater than $12^{\circ}$, based on Laue backreflection techniques was considered defective and was not used in this study. In addition, any samples with defects, such as high angle boundaries (HAB), low angle boundaries (LAB), sliver, freckles and multi-grains were also considered defective and not used in this study.

Approximately, $2.5 \mathrm{~cm}$ long samples were sectioned from the single crystal bars near the bottom of the single crystal for microstructural characterization. The specimens were mounted, ground, and polished to $0.3 \mathrm{~m}$ using common metallographic practices.

\section{Electron Microprobe Analysis}

Electron microprobe analysis (EMPA) was done on all of the ascast specimens in the as-polished condition, using a JEOL
Superprobe 733. The instrument was operated at an accelerating voltage of $15 \mathrm{KeV}$, a take-off angle of $40^{\circ}$, a beam current of 20 $\mathrm{nA}$, and a spot size $\approx 1 \mu \mathrm{m}$. Specific calibration standards were used as references for $\mathrm{Ni}, \mathrm{Cr}, \mathrm{Co}, \mathrm{Mo}, \mathrm{W}, \mathrm{Re}, \mathrm{Ta}, \mathrm{Al}, \mathrm{Ti}$, and $\mathrm{Ru}$. The amount of Hf present in the alloys $(0.1 \mathrm{wt} \%)$ was below the threshold ability for detection of the instrument. Although Hf was not included in the quantitative analysis, Hf was included in the data acquisition. Wavelength dispersive spectroscopy (WDS) was used with TAP crystals to detect W, $\mathrm{Re}, \mathrm{Ta}, \mathrm{Hf}$, and $\mathrm{Al}$ using M $\alpha$ lines for all but the Al. K $\alpha$ was used for Al. A LiF crystal was used to detect $\mathrm{Ni}, \mathrm{Cr}$, and $\mathrm{Co}$ examining $\mathrm{K} \alpha$ lines. For the remaining elements, $\mathrm{Ru}$ and $\mathrm{Mo}$, a PET crystal was used examining L $\alpha$ lines. Each element was counted for $10 \mathrm{sec}$ per point.

Line scans were preformed to measure the compositions. At least three straight lines were used from the center of one dendrite core to the center of an adjacent dendrite core, through the interdendritic region. The individual data acquisition point along the line scan was $\approx 10 \mu \mathrm{m}$ apart with an average line length of $\approx 300 \mu \mathrm{m}$ (the typical primary dendrite arm spacing). Figure 1 shows an example of a typical line scan used. The curves had a minimum or a maximum value at the center of the scan (in the interdendritic region) for each element, depending on the segregation behavior. The partitioning coefficient was then taken as the composition (in wt $\%$ ) of the element at the ends of the line scan, divided by the composition (in wt\%) of the element at the minimum/maximum value in the interdendrite region. This method was developed and chosen over the $15 \times 15$ point matrix scan technique developed by M. N. Gungor [12], due to the potential for discrepancies in measured segregation profiles [13]. Although the $15 \times 15$ point matrix scan produces a concentration versus solid fraction relationship, which is obtained by arranging the points in an either ascending or descending order, based on segregation behavior, misleading results can arise. Since the resulting 225 points obtained in the 15 x 15 point matrix are random, compositions obtained from the points, do not necessarily represent all stages of solidification (e.g., the dendrite core and the interdendritic $\gamma / \gamma$ ' eutectic structure). In addition, point to point fluctuations because of course $\gamma^{\prime}$ precipitates that form during cooling after directional solidification can cause discrepancies [13]. 


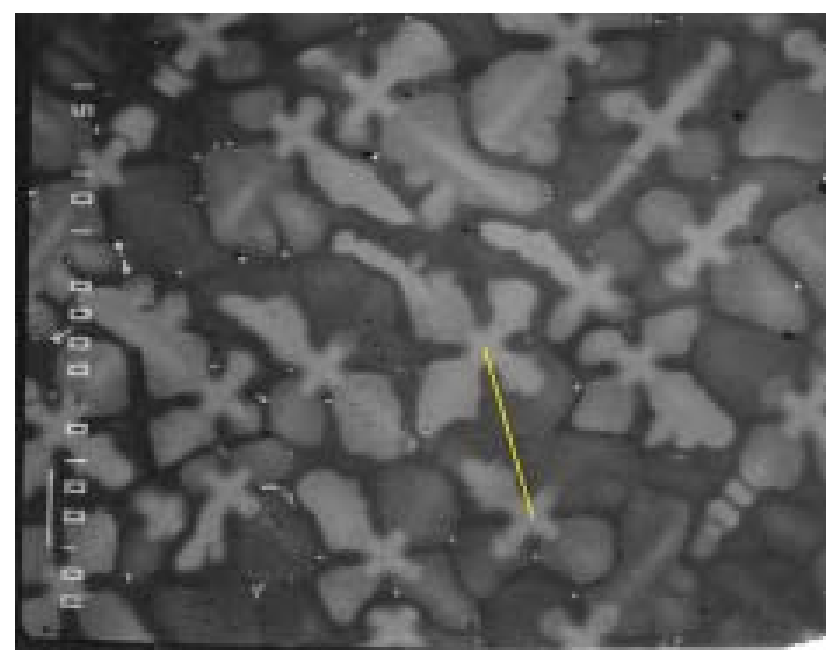

Figure 1: BSE image of LMSX-3 showing a typical line scan used.

\section{Results and Discussion}

\section{Microstructure}

The microstructures of all of the alloys were characterized to evaluate the as-solidified structures and to determine the locations for the compositional analysis using back scattered electron (BSE) microscopy. The as-cast single crystal Ni-base superalloys exhibited a dendritic microstructure typically observed in directionally solidified alloys (Figures 2-4). The high degree of elemental segregation from the dendrite cores to the interdendritic regions is clearly visible. The segregation of each of the elements is discussed individually below for clarity.

\section{Solidification Segregation Analysis of As-Cast Structure}

The as-cast microstructure of all of the alloys was clearly inhomogeneous due to the severe elemental segregation that occurs during solidification. Certain elements preferentially partition to the dendritic core and others the interdendritic regions. The elements that partitioned to the dendrite core included Re, W, Co, and Mo. Elements that tend to partition to the interdendritic region were the $\gamma$ '-formers, including $\mathrm{Ni}, \mathrm{Ti}$, $\mathrm{Ta}$, and $\mathrm{Al}[6,7,12-14]$.

As stated, the general trends for the elemental segregation in Nibase superalloy single crystals are known. However, the degree to which the segregation is affected by changes in the major alloying additions has not been reported. To determine the effects of compositional changes on the segregation behavior, as-cast microstructures were characterized by microprobe techniques to calculate the segregation coefficient, k'. Once the segregation coefficients were determined for all elements, some general trends for segregation were apparent. $\mathrm{Ni}, \mathrm{Ta}, \mathrm{Ti}$, and $\mathrm{Al}$ all show a preference to segregate to the interdendritic region. The segregation behavior, as measured by the partitioning coefficient, k', was then examined as a function of alloy composition. Since at least three line scans were performed on each sample in regions specifically selected to reduce the potential for discrepancies in compositional analysis, the amount of scatter in the measured partitioning coefficients was small, typically less than few percent. If greater levels of scatter were encountered during data analysis, additional line scans were performed.

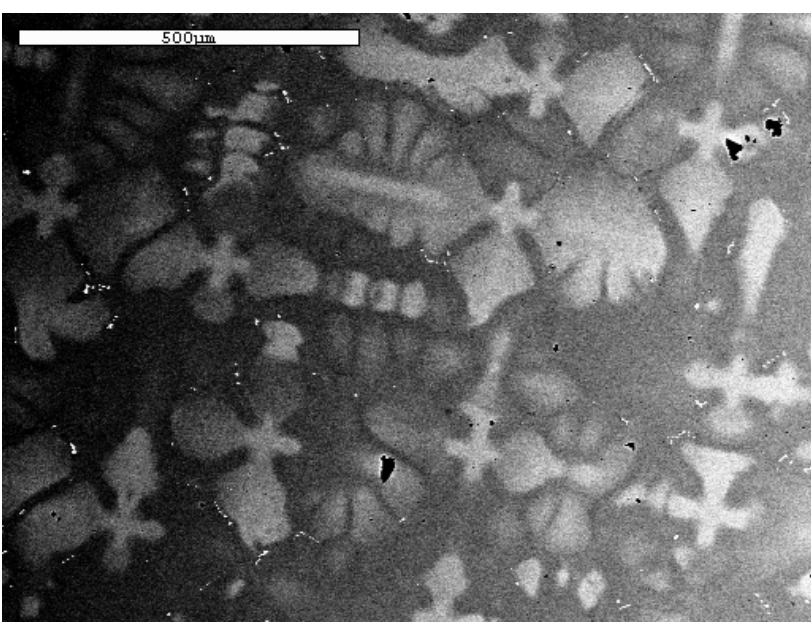

Figure 2: BSE image of LMSX-1 (baseline alloy with $12.2 \mathrm{wt} \%$ $\mathrm{Co}$ ) showing the dendrite cores and interdendritic regions.

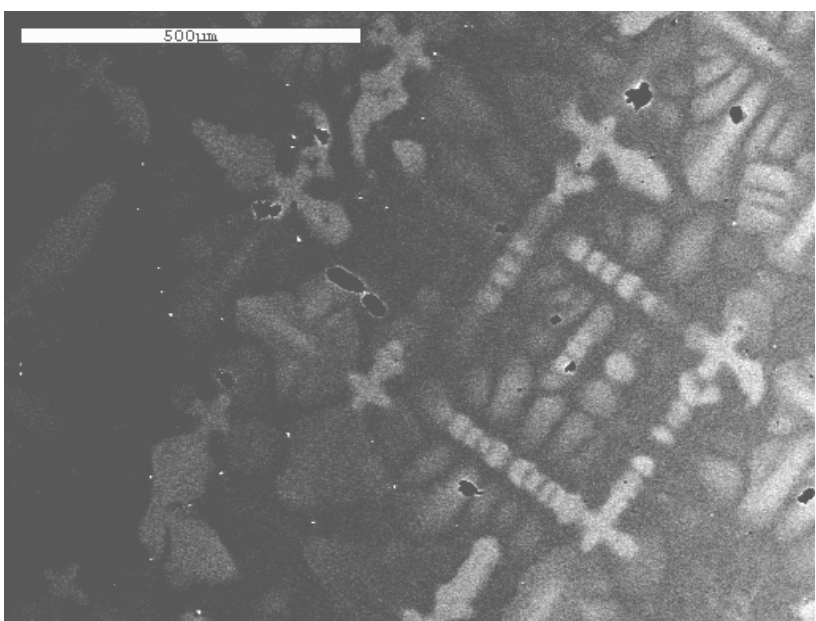

Figure 3: BSE image of LMSX-2 (8 wt $\% \mathrm{Co})$.

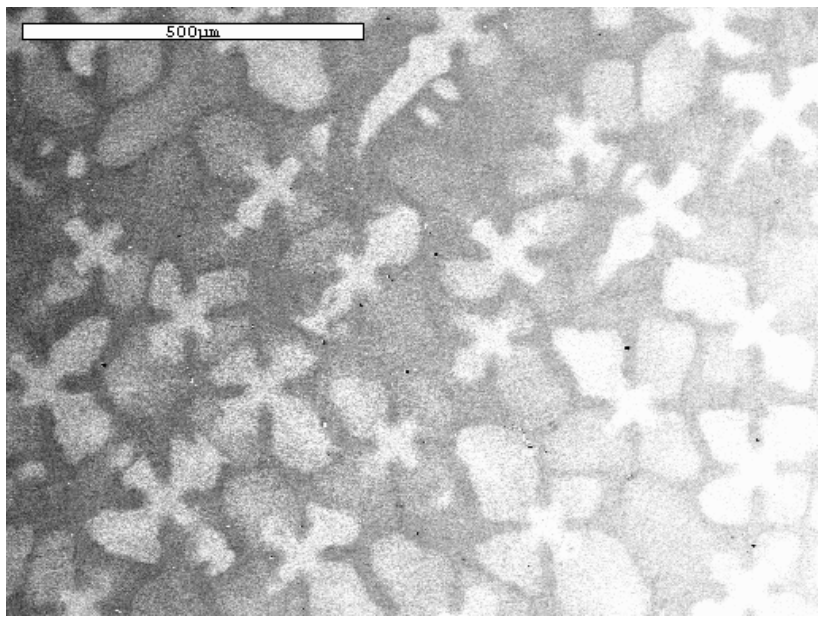

Figure 4: BSE image of LMSX-3 (4 wt $\%$ Co) 
Ta had the strongest degree of segregation to this region, followed by $\mathrm{Al}$ and $\mathrm{Ni}$. The dendrite core was enriched in $\mathrm{W}$, $\mathrm{Mo}, \mathrm{Co}$, and $\mathrm{Cr}$. $\mathrm{Re}$ exhibited the greatest degree of segregation, followed by $\mathrm{W}, \mathrm{Mo}$, and Co. Cr was only slightly enriched in the dendrite core. These results follow the general segregation trends reported for commercially alloys $[6,12,15]$, as well as, those reported for model SX alloys $[7,13,16]$.

To develop an understanding of the compositional effects on segregation, all of the alloys in this study were compared to the baseline alloy (LMSX-1)

\section{Cobalt Effect on Segregation}

To examine the effect of Co on segregation, the k' values for the elements in LMSX-1 (12.2 wt\% Co), LMSX-2 (8 wt\% Co) and LMSX-3 (4 wt $\%$ Co) were calculated and compared. The results are shown in Figures 5 (interdendritic region segregation) and 6 (dendrite core segregation). Modifying the Co content resulted in changes to the segregation behavior of all of the elements in the alloy. However, the greatest effect was observed in the Re segregation. The $\mathrm{k}_{\mathrm{Re}}$ decreased by almost one half when the Co level was increased from the lowest to the highest level. The segregation of $\mathrm{W}\left(\mathrm{k}_{\mathrm{W}}{ }\right)$ was also decreased with increasing $\mathrm{Co}$, but to a lesser extent than Re. Co itself also showed a slight decrease in k' when the Co content was increased. Cr showed only a limited degree of segregation to the dendrite core, but the segregation of $\mathrm{Cr}$ was slightly decreased with increasing Co content. When looking at the elements that partition to the interdendritic region, $\mathrm{Ni}$ segregated to a greater extent with increasing Co content. Increasing the Co though resulted in a decrease in the degree of Ta and Al segregation, by increasing the k' for both elements. In general, increasing the Co content resulted in decreased segregation of all elements, with the exception of a slight increase in the $\mathrm{Ni}$ segregation. In particular, the most strongly segregating elements, Ta and Re, exhibited a significant decrease in the tendency for segregation with increasing Co content.

\section{Chromium Effect on Segregation}

The effect of the Cr content on segregation of all elements in the alloy was examined by comparing the individual segregation coefficients for each element in alloys LMSX-5 (2.1 wt\% Cr), LMSX-1 (4 wt \% Cr), and LMSX-4 (6.15 wt \% Cr). Figure 7 illustrates the effect of $\mathrm{Cr}$ content on the segregation of those elements that segregate to the dendrite core, and the segregation behavior of the elements that segregate to the interdendritic region is shown in Figure 8. Re was the element that was most affected, of all of the elements that segregated to the dendrite core, by increasing the $\mathrm{Cr}$ content of the alloy. The segregation behavior of $\mathrm{W}$ and Co was also affected by the Cr content, but to a lesser degree. Cr exhibited only a weak tendency to partition to the dendrite core. In the baseline alloy with $4 \mathrm{wt} \% \mathrm{Cr}, \mathrm{Cr}$ was observed to exhibit a slightly greater tendency to partition to the dendrite then did the alloys with either increased or decreased $\mathrm{Cr}$ contents. The segregation of $\mathrm{Ta}$ to the interdendritic region increased with the increasing $\mathrm{Cr}$ content; whereas, the segregation of $\mathrm{Ni}$ and $\mathrm{Al}$ to the interdendritic region did not appear to be effect by the $\mathrm{Cr}$ content of the alloy. In general, increasing the $\mathrm{Cr}$ content of the alloy had the biggest impact on the segregation of the refractory elements, $\mathrm{W}, \mathrm{Re}$, and $\mathrm{Ta}$, which exhibited an increase in the degree of segregation with increasing $\mathrm{Cr}$ content. The segregation behavior of the other elements in the alloy did not appear to be significantly affected by changing the $\mathrm{Cr}$ content of the alloy.

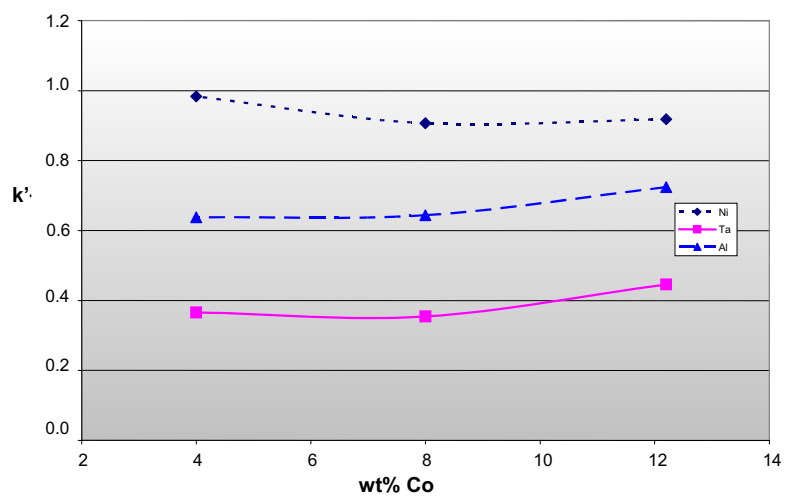

Figure 5: The effect of Co concentration on the segregation of elements that segregate to the interdendritic region.

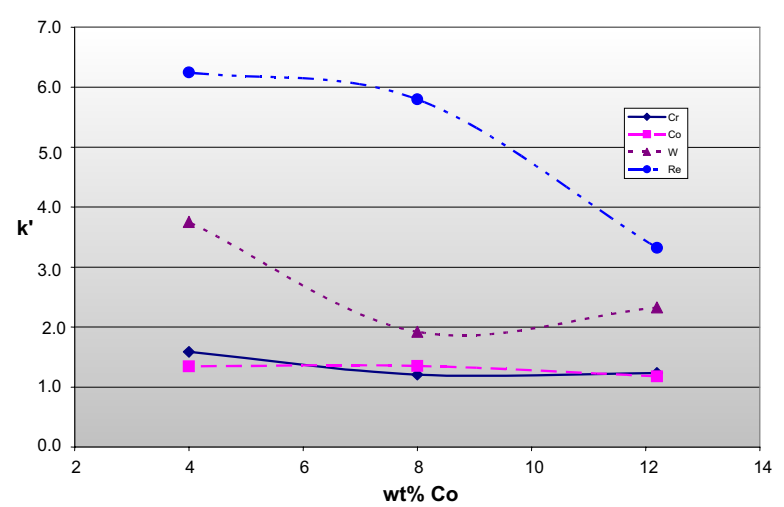

Figure 6: The effect of Co concentration on the segregation of elements that segregate to the dendrite core.

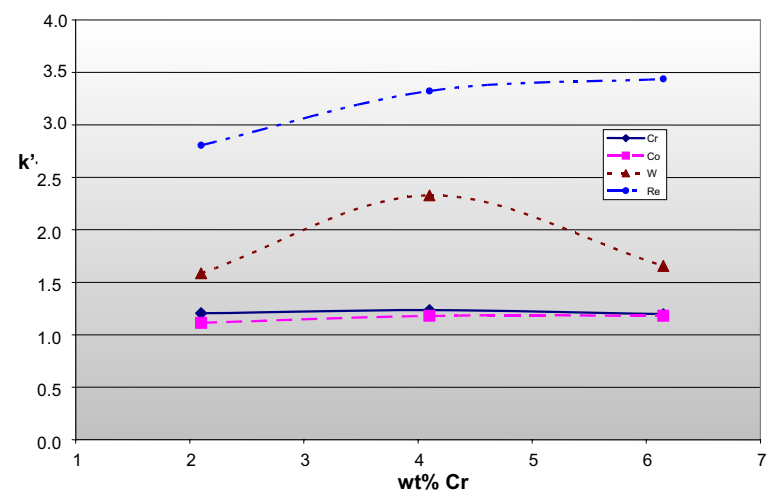

Figure 7: The effect of $\mathrm{Cr}$ concentration on the segregation of elements that segregate to the dendrite core. 


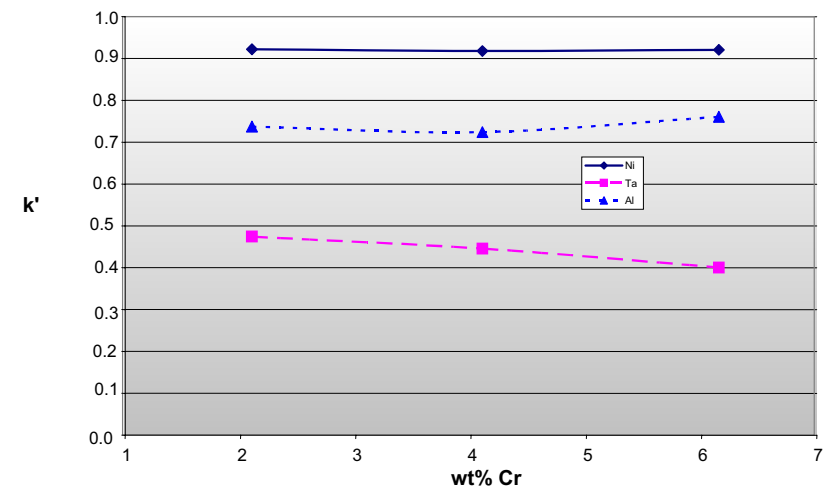

Figure 8: The effect of $\mathrm{Cr}$ concentration on the segregation of elements that segregate to the interdendritic region.

\section{$\underline{\text { Re Effect on Segregation }}$}

Re content is typically used as a technique to differentiate between the various generations of superalloys. In this study, the alloys examined included Re levels typical of all three generations of alloys and an alloy with elevated levels of Re. The alloys selected for evaluation were LMSX-9 (0 wt\% Re), LMSX-10 (2.9 wt\% Re), LMSX-1 (5.85 wt \% Re), and LMSX$11(8.9 \mathrm{wt} \% \mathrm{Re})$. The segregation coefficients for those elements that partition to the dendrite core (Figure 9) and the interdendritic region (Figure 10) were measured for each of these alloys. Of the elements that partition to the dendrite core, the Re content was observed to have the greatest impact on the segregation of Re itself. As the amount of Re was increased in the alloy, the tendency for the Re segregation to the dendrite core increased. In general, Re exhibited the strongest degree of segregation, of any element in all of the alloys. An increase in Re content also resulted in an increased degree of segregation of $\mathrm{W}$, and to a lesser extent $\mathrm{Cr}$ and even Co. When examining the segregation coefficient for those elements that segregated to the interdendritic region, the segregation coefficient of Ta, and to a lesser extent $\mathrm{Al}$, followed by $\mathrm{Ni}$, exhibited increasing degrees of segregation with increasing Re content. The effect of Re on the segregation of the elements can clearly be seen by looking at the segregation behavior of $\mathrm{Ni}$. The first generation superalloy (LMSX-9, $0 \mathrm{wt} \% \mathrm{Re}$ ), had a calculated k' for Ni of almost 1, indicating almost no segregation preference between the dendrite and the interdendritic region. As the Re content was increased, the $\mathrm{k}$ ' for $\mathrm{Ni}$ decreased steadily until reaching a minimum in the LMSX-11 alloy, indicating that the degree of segregation of Ni steadily increased with increasing Re content.

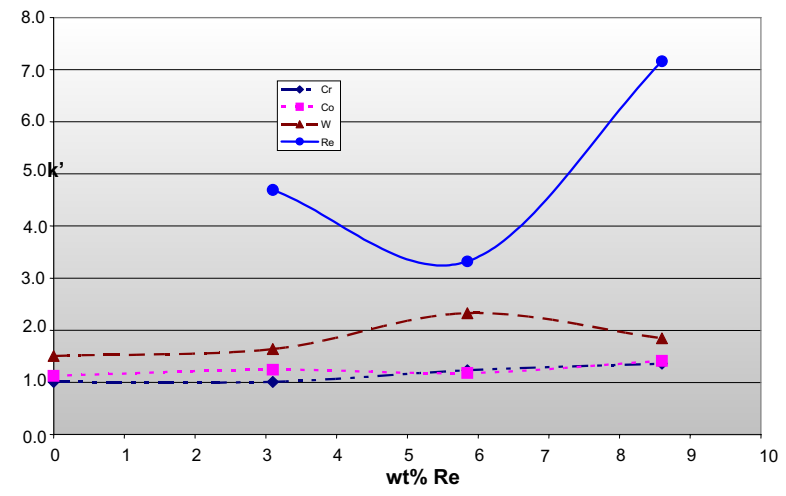

Figure 9: The effect of Re concentration on the segregation of elements that segregate to the dendrite core.

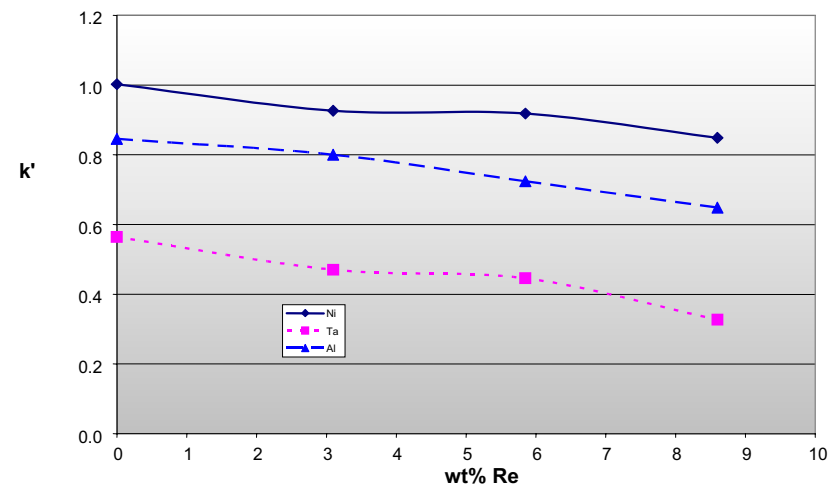

Figure 10: The effect of Re concentration on the segregation of elements that segregate to the interdendritic region.

Molybdenum Effects on Segregation

A Mo addition was also examined, since this element is still used at low levels in many second and third generation alloys. LMSX-8 is a modified version of LMSX-1, with the addition of $1 \mathrm{at} \%(1.6 \mathrm{wt} \% \mathrm{Mo})$. When Mo was added to the alloy, the segregation of the elements that typically partition to the dendrite core (i.e., Re, W, Co, and Cr) exhibited a decrease in the degree of segregation (Figure 11). However, the effect of Mo additions on the segregation of Co was very limited, with virtually no change in Co segregation. The Mo additions appeared to have the greatest impact on the segregation of $\mathrm{W}$ and Re, and to a lesser degree, Ni. Mo appears to decrease the segregation of $\mathrm{Cr}\left(\mathrm{k}^{\prime}{ }_{\mathrm{Cr}}\right)$ and actually appears to change the direction of segregation of $\mathrm{Cr}$, since the $\mathrm{Cr}$ appeared to be slightly enriched in the interdendritic region in the Mocontaining alloy. The segregation coefficient of Mo indicates that it partitions to the interdendritic region (shown by a single point in Figure 12). The Mo addition resulted in a slight reduction in the segregation of elements that partition to the interdendritic region (Figure 12). The segregation of $\mathrm{Al}$ exhibited the greatest decrease with increasing Mo content. The segregation of $\mathrm{Ni}$ was also decreased but to a lesser extent. Mo additions did not appear to have a significant effect on the segregation of Ta. 


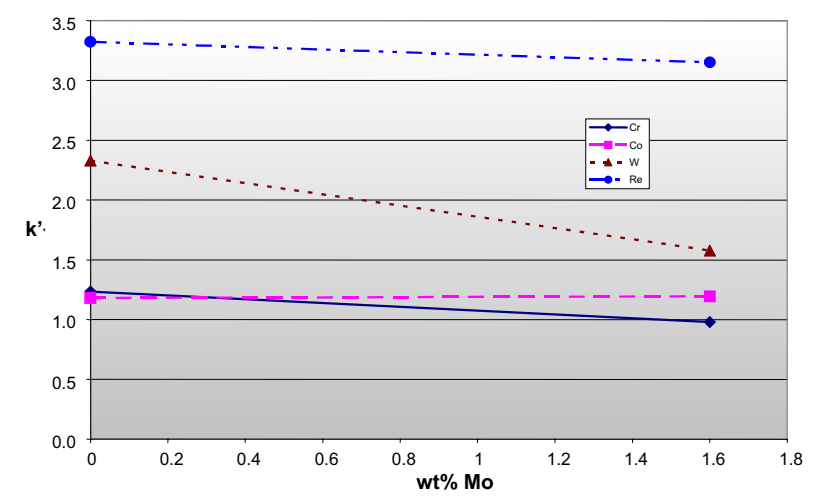

Figure 11: The effect of Mo additions on the segregation of elements that segregate to the dendrite core.

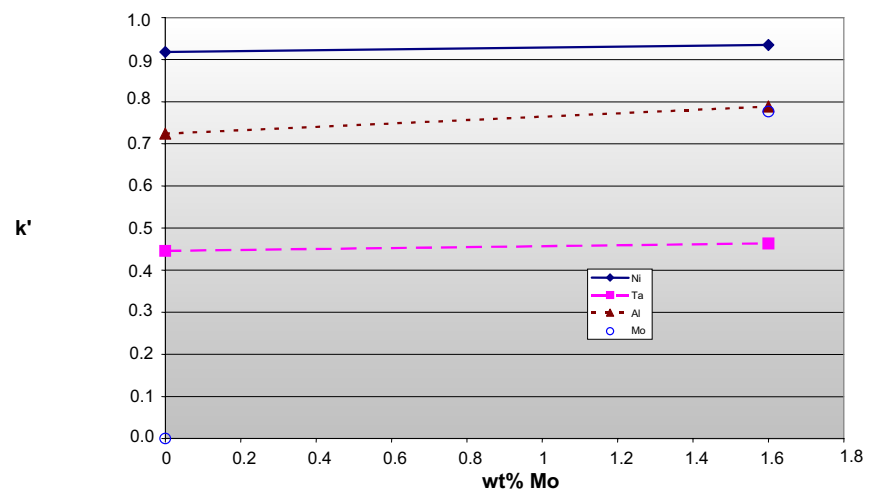

Figure 12: The effect of Mo additions on the segregation of elements that segregate to the interdendritic region.

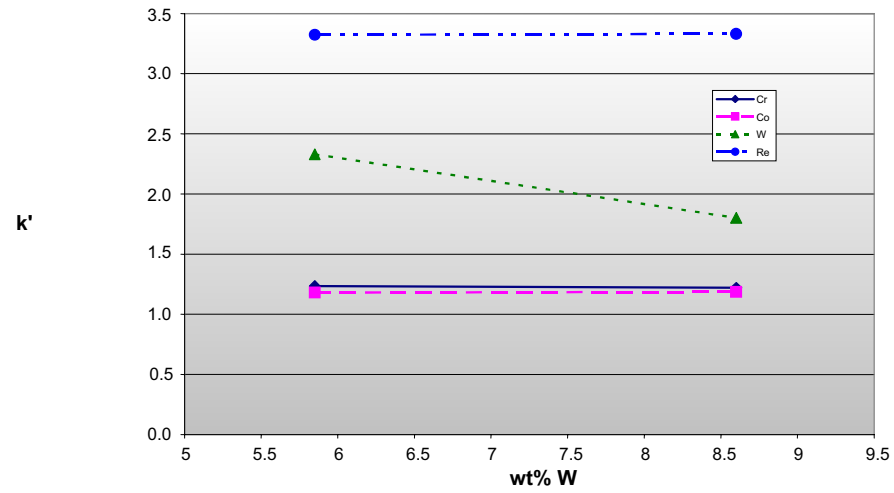

Figure 13: The effect of increasing $\mathrm{W}$ to baseline LMSX-1 on the segregation of elements segregating to the dendrite core.

\section{Tungsten Effect on Segregation}

To examine the effect $\mathrm{W}$ additions on the segregation behavior an alloy which contained an additional 1 at $\% \mathrm{~W}$ was compared to the baseline LMSX-1 ( 2 at $\% \mathrm{~W}, 5.95 \mathrm{wt} \% \mathrm{~W})$. The alloy with increased $\mathrm{W}$ level was designated LMSX-8 (3 at\% W, 8.6 $\mathrm{wt} \% \mathrm{~W})$. The segregation coefficients were determined for the elements that segregate to the dendrite cores (Figures 13) and to the interdendritic region (Figure 14) and evaluated. The additional 1 at $\%$ of $\mathrm{W}$ did not appear to have a significant effect on the segregation of most of the elements that partition to the dendrite core (i.e., Re, Co, and $\mathrm{Cr}$ ). However, $\mathrm{W}$ additions did have a significant effect on the segregation of $\mathrm{W}$ itself. The increase in $\mathrm{W}$ content resulted in a decrease in the segregation of W. The $\gamma$ ' formers and those elements segregating to the interdendritic (i.e., $\mathrm{Ni}, \mathrm{Ta}$, and $\mathrm{Al}$ ) all exhibited a slight decrease in the segregation coefficient (indicating a slight increase in segregation) with an increase in the $\mathrm{W}$ content.

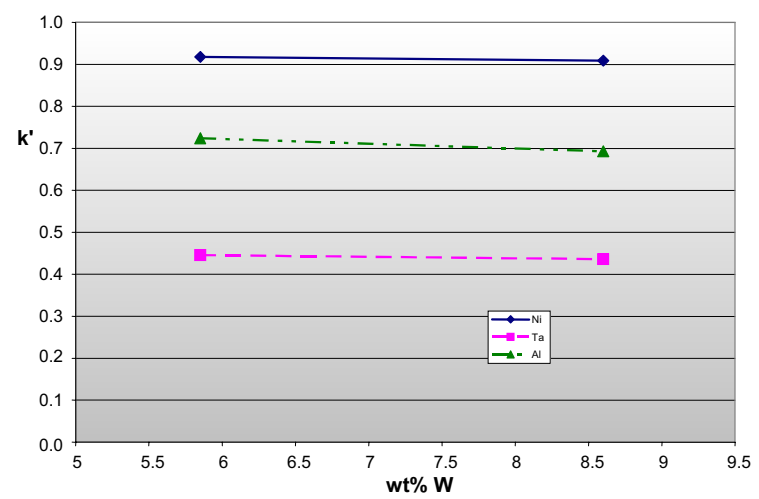

Figure 14: Effect of increasing W to baseline LMSX-1 on the segregation of elements segregating to the interdendritic region.

\section{$\underline{\text { Ruthenium Effect on Segregation }}$}

$\mathrm{Ru}$ was added at two different levels in two alloys, LMSX -16 (1 at $\% \mathrm{Ru}, 1.6 \mathrm{wt} \% \mathrm{Ru})$ and LMSX-17 (2 at \% Ru, $3.2 \mathrm{wt} \% \mathrm{Ru})$. The greatest effect of increased $\mathrm{Ru}$ contents was on the segregation of $\mathrm{Re}$ (Figure 15). The addition of $\mathrm{Ru}$ first decreased the segregation of Re, then further additions resulted in an increase in the Re segregation. $\mathrm{Ru}$ also increased the segregation of $\mathrm{Cr}$ and $\mathrm{Co}$ at a fairly constant rate. The segregation of $\mathrm{W}$, decreased as $\mathrm{Ru}$ was added (Figure 15). $\mathrm{Ru}$ itself partitioned to the dendritic cores, initially about the same degree as either Co or $\mathrm{Cr}$, but the segregation was observed to decrease with increasing Ru content (Figure 15). The effect of the $\mathrm{Ru}$ addition on segregation of elements that segregate to the interdendritic region was similar to that observed in the alloys with varying $\mathrm{Re}$ content (Figure 16). The segregation coefficient ( $\left.\mathrm{k}^{\prime}\right)$ for both Ta and Al initially decreased with the addition of the $1.6 \mathrm{wt} \% \mathrm{Ru}$. However, the segregation coefficient of $\mathrm{Ta}$ and $\mathrm{Al}$ then increased, with the addition of another $1.6 \mathrm{wt} \% \mathrm{Ru}$, to a level greater than that observed in the baseline alloy $(0 \mathrm{wt} \% \mathrm{Ru})$. The segregation coefficient of $\mathrm{Ni}$ appeared to decrease slightly as $\mathrm{Ru}$ was added. 


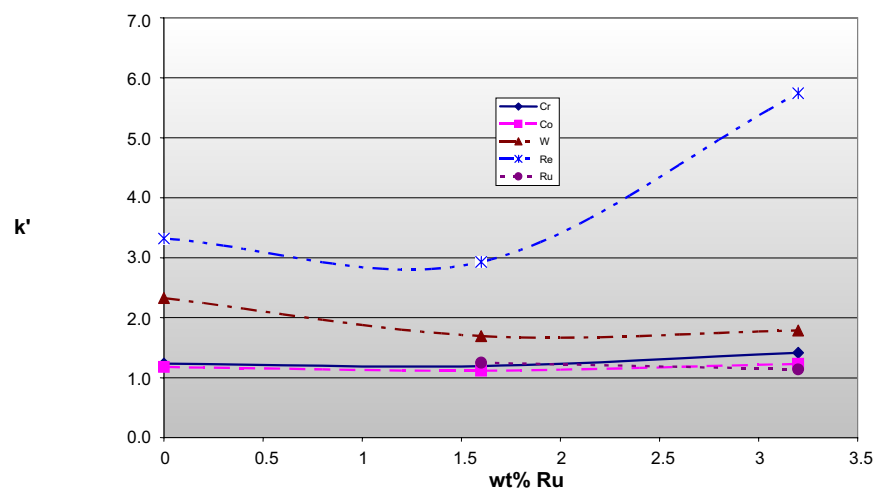

Figure 15: The effect of an addition of Ru to baseline LMSX-1 on the segregation of elements segregating to the dendrite core.

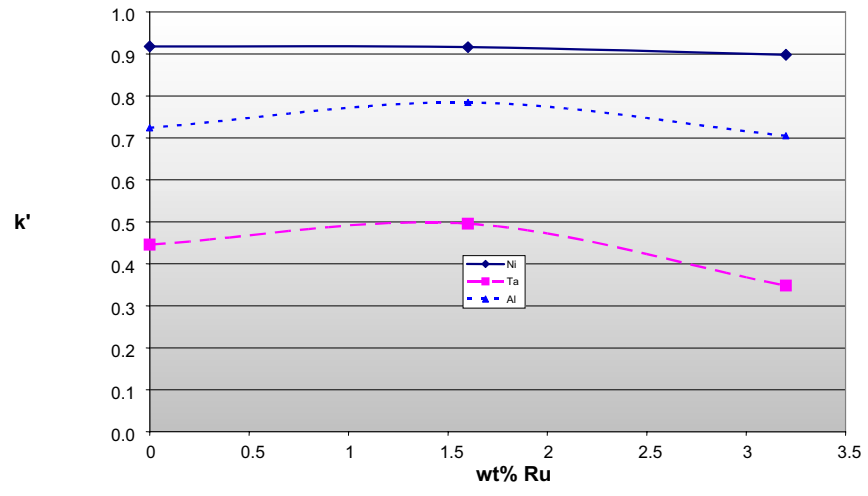

Figure 16: The effect of an addition of Ru to baseline LMSX-1 on the segregation of elements segregating to the interdendritic region.

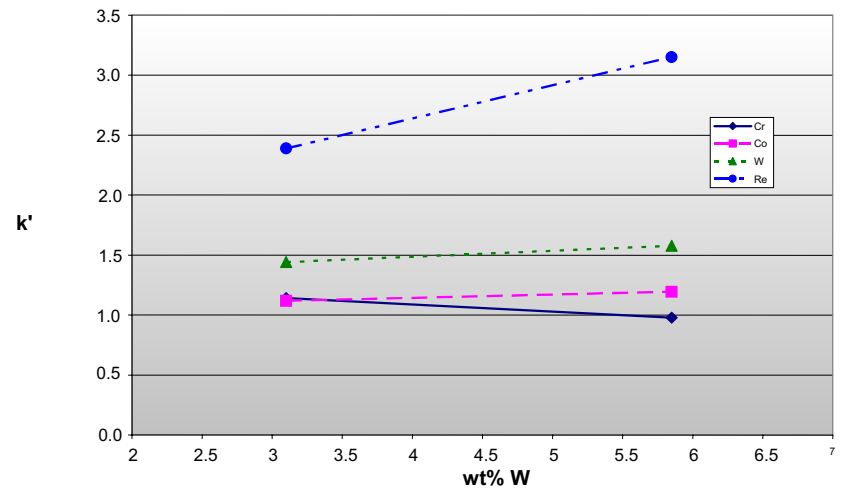

Figure 17: Segregation effect due to the substitution of Mo for $\mathrm{W}$ on the elements segregating to the dendrite core.

\section{Substitution of Molybdenum for Tungsten}

Although the effect of Mo additions on the segregation behavior was discussed previously, a separate alloy was examined where the Mo addition was made with an atom-for-atom substitution for W (LMSX-7). Considering the alloys with constant Mo content and then decreasing the $\mathrm{W}$ content from LMSX-8 (2 at $\%$ ) to LMSX-7 (1 at\%), the decreased $\mathrm{W}$ content resulted in a decrease in the segregation coefficient for those elements that segregate to the dendrite core (Figure 17). The greatest changes in segregation were observed in Re, followed by W and then, to a much lesser degree, Co. As W was decreased, the segregation of $\mathrm{Cr}$ appeared to reverse direction in that the $\mathrm{Cr}$ was observed to partition to the dendrite core in the LMSX-7 alloy and to the interdendritic region in LMSX-8. The partition trends for the elements that partition to the interdendritic region also exhibited a change with decreasing $\mathrm{W}$ content (Figure 18). The degree of segregation for both $\mathrm{Ni}$ and $\mathrm{Ta}$ decreased as the amount of $\mathrm{W}$ decreased. Mo appears to segregate more strongly with a decrease in $\mathrm{W}$. The Mo addition and reduced $\mathrm{W}$ cause the Al to segregate more to the dendrite core than the interdendritic, although $\mathrm{Al}$ was observed to partition to the interdendritic region in all other alloys.

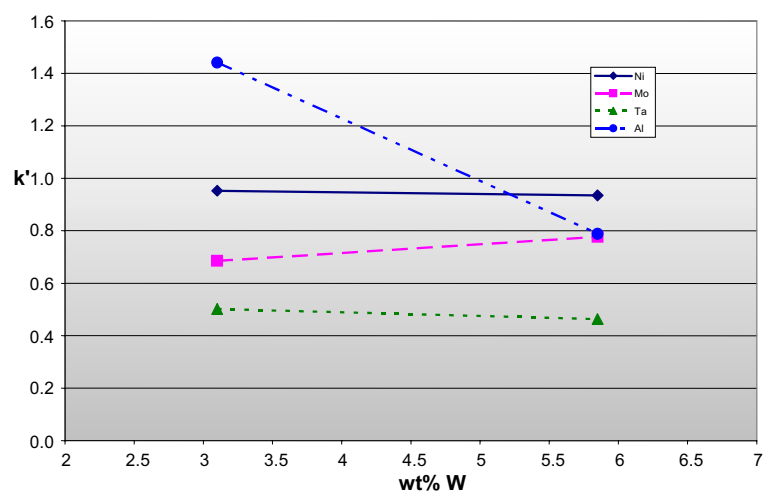

Figure 18: Segregation effect due to the substitution of Mo for $\mathrm{W}$ on the elements segregating to the interdendritic region.

\section{Conclusions}

An increase in the Co of the alloy decreased the segregation of elements that segregate to the dendrite core ( $\mathrm{Re}, \mathrm{W}, \mathrm{Cr}$, and $\mathrm{Co}$ ), as well as some of those that segregate to the interdendritic region ( $\mathrm{Ta}$ and $\mathrm{Al})$. The segregation of $\mathrm{Ni}$ increased with increasing Co content. Additions of $\mathrm{Co}$, therefore, would be expected to result in an alloy that exhibits less as-solidified segregation, which would also be expected to reduce the heat treatment requirements of the alloy.

As more $\mathrm{Cr}$ was added to the alloy, Re, W, and Co exhibited greater levels of segregation to the dendrite core. The amount of segregation due to the $\mathrm{Cr}$ addition does not affect the segregation of $\mathrm{Cr}$, nor did it change the segregation of $\mathrm{Ni}$. Ni still segregates to the interdendritic, and $\mathrm{Cr}$ partitioned to the dendrite core. Increasing $\mathrm{Cr}$ also tended to increase the segregation of $\mathrm{Ta}$. Increased $\mathrm{Cr}$ levels appeared to decrease the segregation of Al slightly.

Increasing the amount of $\mathrm{Re}$ in the alloy tended to increase the segregation of all of the elements in this study $(\mathrm{Ni}, \mathrm{Cr}, \mathrm{Co}, \mathrm{W}$, $\mathrm{Re}, \mathrm{Ta}$, and $\mathrm{Al}$ ). With $\mathrm{Re}$ not present, $\mathrm{Ni}$ exhibited no preference (dendrite core or interdendritic region) for segregation. However, as Re was added to the alloy, the 
segregation of $\mathrm{Ni}$ to the interdendritic region was observed to steadily increase.

An addition of Mo ( $1 \mathrm{at} \%, 1.6 \mathrm{wt} \%$ ) decreased the segregation of $\mathrm{W}$, and to a lesser extent Re and Cr. Co did not exhibit any change in the segregation behavior with Mo additions. The Mo addition also tended to decrease the segregation of the elements that partitioned to the interdendritic region $(\mathrm{Ni}, \mathrm{Ta}$, and $\mathrm{Al})$. Mo additions would be expected to result in an alloy that exhibits less as-solidified segregation, which would also be expected to reduce the heat treatment requirements of the alloy.

Increasing the amount of $\mathrm{W}$ present in the alloy had no apparent effect on the segregation of $\mathrm{Re}, \mathrm{Cr}$, and $\mathrm{Co}$. Increased $\mathrm{W}$ content, though did decrease the segregation of $\mathrm{W}$ itself. Ni, Ta, and $\mathrm{Al}$ show slight increases in segregation as the amount of $\mathrm{W}$ was increased.

Adding $\mathrm{Ru}$ to the alloy causes the segregation of Re to initially decrease and then increase. This addition of $\mathrm{Ru}$ also decreases the segregation of $\mathrm{W}$, while $\mathrm{Cr}$ and $\mathrm{Co}$ exhibited a greater tendency to segregate. The segregation of $\mathrm{Ni}$ was only slight affected by the increase in Ru. Al and Ta both follow the same trend as Re above, initially decreasing and then increasing.

Decreasing W, while Mo was added, resulted in an increase in segregation for $\mathrm{Re}$ as $\mathrm{W}$ is added. The segregation of $\mathrm{W}$ increases slight as well. The segregation of $\mathrm{Cr}$ does not change as $\mathrm{W}$ is added back, and Co begins to segregate less as $\mathrm{W}$ is added to the alloy. Al begins to partition to the dendrite core with low amounts of $\mathrm{W}$, and as $\mathrm{W}$ is added, it partitions back to the interdendritic region. $\mathrm{Ni}$ and $\mathrm{Ta}$ both show a slight increase in segregation as $\mathrm{W}$ is added. Finally, the segregation of Mo begins to increase as $\mathrm{W}$ is added into the system.

Based on these results, it is now possible to better understand the heat treatment requirements for some commercial alloys. For example, the two third generation alloys, Rene' N6 and CMSX10 , both contain about $6 \mathrm{wt} \% \mathrm{Re}$, but have very different solution heat treatment schemes. The Rene' N6 alloy which also includes greater levels of Mo and $\mathrm{Co}$, which would be expected to result in reduced levels of segregation, requires much lower temperature and shorter duration solution heat treatments than CMSX-10 [3,17]

\section{Acknowledgements}

The authors would like to acknowledge the support of Wayne Acree and the staff of the Major Analytical Instrument Center (MAIC) at the University of Florida. This material is based on work supported by the National Science Foundation under Grant No. 0072671.

\section{References}

1. "Directionally Solidified and Single Crystal Superalloys", from "Heat Resistant Materials - ASM Specialty Handbook", Ed., J. R. Davis, ASM International, Materials Park, OH, pp. 255-271, (1997).

2. C.T. Sims, "Superalloys: Genesis and Character", in Superalloys II, Eds., C. Sims, N. Stoloff, and W. Hagel, J. Willey and Sons, NY, NY, pp. 3-26, (1987).
3. W.S. Walston, K.S. O’Hara, , E.W. Ross, T.M. Pollock, W.H. Murphy, "René N6: Third Generation Single Crystal Superalloy", Eds. R.D. Kissinger, D.J. Deye, D.L. Anton, A.D. Cetel, M.V. Nathal, T.M. Pollock and D.A. Woodford, Superalloys 1996, TMS, pp. 27-34 (1996).

4. F. J. Fela, "Influence of Chemical Composition Variations on the Elemental Solidification Segregation Segregation in Nickel-Base Single Crystal Superalloy", Maser's Thesis, University of Florida, May 2000.

5. P. Caron, "Design of Superalloys for Single Crystal Blade Applications: A 20 Year Experience", Materials Design Approaches and Experiences, TMS, (2001), pp. 1-14.

6. M. Durand-Charee, "The Microstructure of Superalloys", Gordon and Breach Science Publishers, Toronto, Canada, p. 60-69, (1997).

7. T.M. Pollock, W.H. Murphy, E.H. Goldman, D.L. Uram, and J.S. Tu, "Grain Defect Formation During Directional Solidification of Niclel Base Single Crystals", Superalloys 1992, Eds. S.D. Antolovich, R.W. Stusrud, R.A. MacKay, D.L. Anton, T. Khan, R.D. Kissinger and D.L. Klarstron, TMS, Warrendale, PA, pp. 125-134, (1992).

8. M. Gell, D.N. Duhl, K. Gupta, and K Sheffler, "Advanced Superalloys Airfoils", Journal of Metals, Vol. 39, No. 7, pp. 11-15, (1987).

9. A. Willis and D. McCartney, "A Comparative Study of Solidification Features in Nickel-Base Superalloy: Microstructural Evolution and Microsegregation", Mat. Sci. \& Eng, Vol. A 145, No. 2, pp. 223-232, (1991).

10. P. Caron and T. Kahn, "Improvement in Crep strength in a Nickel-base Single Crystal Superalloy by Heat-treatment", Journal of Mat. Sci \& Eng, Vol. 61, pp. 173-176, (1983).

11. G. E. Fuchs, Journal of Mat. Eng. and Pref., "Improvement of Creep Strength of a Third Generation, Single Crystal Nibase Superalloy by Solution Heat Treatment", Vol. 11, pp. 19-25, (2002).

12. M.N. Gungor, "A Statistically Significant Experimental Technique for Investigating Microsegregation in Cast Alloys", Met. Trans., 20A, p.2529-2533, (1989).

13. K.A. Al-Jarba and G.E. Fuchs, "Effect of Carbon Additions on the As-cast Microstructure and Defect Formation of a Single Crystal Ni-base Superalloy", Mat. Sci. and Eng'g, Vol. A373, pp. 255-267, (2004).

14. G. E. Fuchs, Journal of Mat. Sci. \& Eng., "Solution Heat Treatment Response of a Third Generation Single Crystal Ni-base Superalloy", Vol. A300, pp. 52-60, (2001).

15. T.M. Pollock and W.H. Murphy, "The Breakdown of Single-Crystal Solidification in High Refractory NickelBase Alloys", Met Trans A, Vol. 27A, pp. 1081-1089, (1996).

16. Phase Diagrams, ASM Handbook, Vol. 3, $10^{\text {th }}$ Edition, ASM International, Metals Park, OH (1991).

17. G.L. Erickson, "The Development and Application of CMSX-10”, Eds. R.D. Kissinger, D.J. Deye, D.L. Anton, A.D. Cetel, M.V. Nathal, T.M. Pollock and D.A. Woodford, Superalloys 1996, TMS, Warrendale, PA, pp. 35-44, (1996). 